\title{
In and Beyond COVID-19: US Academic Pharmaceutical Science and Engineering Community Must Engage to Meet Critical National Needs
}

\author{
Vadim J. Gurvich ${ }^{1,2,4}$ and Ajaz S. Hussain ${ }^{1,3}$
}

Received 12 May 2020; accepted 15 May 2020; published online 24 May 2020

\begin{abstract}
The supply of affordable, high-quality pharmaceuticals to US patients has been on a critical path for decades. In and beyond the COVID-19 pandemic, this critical path has become tortuous. To regain reliability, reshoring of the pharmaceutical supply chain to the USA is now a vital national security need. Reshoring the pharmaceutical supply with old know-how and outdated technologies that cause inherent unpredictability and adverse environmental impact will neither provide the security we seek nor will it be competitive and affordable. The challenge at hand is complex akin to redesigning systems, including corporate and public research and development, manufacturing, regulatory, and education ones. The US academic community must be engaged in progressing solutions needed to counter emergencies in the COVID-19 pandemic and in building new methods to reshore the pharmaceutical supply chain beyond the pandemic.
\end{abstract}

KEY WORDS: COVID-19; pharmaceuticals; shortages; manufacturing; re-shoring; quality assurance; NIPTE; education.

\section{INTRODUCTION}

The supply of affordable, high-quality pharmaceuticals to US patients has been on a critical path for decades $(1,2)$. In and beyond the COVID-19 pandemic, this critical path has become tortuous. To regain reliability, reshoring of the pharmaceutical supply chain to the USA is now a vital national security need $(3,4)$.

Reshoring the pharmaceutical supply with old know-how and outdated technologies that cause inherent unpredictability and adverse environmental impact neither will provide the security we seek nor will it be competitive and affordable. The challenge at hand is complex akin to redesigning systems, including corporate and public research and development, manufacturing, regulatory, and education ones. The US academic community must be engaged in progressing solutions needed to counter emergencies in the COVID-19

Guest Editors: Ajaz S. Hussain, Kenneth Morris, and Vadim J. Gurvich

${ }^{1}$ The National Institute for Pharmaceutical Technology and Education (NIPTE), Inc., Minneapolis, Minnesota 55414, USA.

${ }^{2}$ Institute for Therapeutics Discovery and Development, College of Pharmacy, University of Minnesota, Minneapolis, Minnesota 55414, USA.

${ }^{3}$ Arnold and Marie Schwartz College of Pharmacy and Health Sciences, Brooklyn, New York 11201, USA.

${ }^{4}$ To whom correspondence should be addressed. (e-mail: vadimg@umn.edu) pandemic and in building new methods to reshore the pharmaceutical supply chain beyond the pandemic.

The National Institute for Pharmaceutical Technology and Education (NIPTE), incorporated in 2005 as an academic multi-institutional collaboration, is now a mature research and education-based organization of 16 leading schools of pharmacy and chemical engineering and a medical school. The NIPTE has a long history of scientific collaboration with the US FDA that supports it under its Critical Path Initiative. The NIPTE is now ready to engage with patient advocacy, political, commercial, and regulatory stakeholders to contribute its integrated pharmaceutical science, technology, and engineering expertise and capabilities to serve the needs of the nation in and beyond the COVID-19 pandemic. This article highlights how the NIPTE is engaging in this endeavor.

\section{IN THE COVID-19 PANDEMIC}

Drug shortages of injectable and small-volume parenteral products represent some of the most severe threats to the ability of the nation's healthcare system to care for COVID-19 patients. For COVID-19 patients to be placed on ventilators and to be maintained in the state of ventilation, several injectable drugs, such as propofol, midazolam, lorazepam, fentanyl, norepinephrine, succinylcholine, hydromorphone, and morphine, are needed. These drugs are in short supply and have been for quite some time (5). These shortages call into question the current antiquated 
global drug supply system based on cost alone. To be a part of the solution, the NIPTE has engaged with the US FDA and other federal entities to discuss and evolve its proposal to establishing a platform for the rapid pharmaceutical manufacturing of injectable drugs in the USA, starting from building blocks readily available from the US chemical industry.

The proposed NIPTE platform aims to manufacture the chemical substances, both active pharmaceutical ingredients (API) and excipients, in the USA to minimize dependence on foreign suppliers in Asia or Europe and then rapidly convert these into sterile injectable or small-volume parenteral products. The chemical synthesis is proposed to be carried out in flow reactors fitted with inline purification modules, and process monitors that feed the API into continuous crystallization conditions for subsequent formulation in a series of closely linked steps. This platform for API and injectable drug product manufacturing is designed to be scalable and with a specific focus on ensuring the highest quality and meeting the required standards for even the sickest patients.

\section{BEYOND THE COVID-19 PANDEMIC}

The task of bringing pharmaceutical manufacturing back to the country is monumental and represents a formidable challenge. It would require a concerted effort by the US government, academia, and industry with broad support from the general public. The aim must be to create a series of economic, financial, and regulatory measures to incentivize industry. Just like for every other aspect of the American enterprise, innovation is the key to success. Significant investments will be required to instigate innovation in pharmaceutical science and engineering. The new regulatory climate must favor a quick adaptation of the newly created innovative technologies (Fig. 1).

From a technological perspective, the effort will require four fundamental elements: pharmaceutical "new prior" knowledge, innovation in advanced manufacturing, and training and education of pharmaceutical scientists, engineers, and manufacturing workforce. Pharmaceutical "New Prior" Knowledge. It is a concept recently introduced by the NIPTE (2). It is based on synthesizing the existing prior knowledge from the time the original drug was approved with the new, state-of-art technologies and methodologies. The goal is to identify gaps, which will constitute new knowledge, that hinder the efficient development and manufacturing of generic drug products.

Innovative Advanced Manufacturing. While most advanced tools and cutting-edge technologies are used in designing and developing new therapies, drug manufacturing lags and is mostly outdated by comparison with other industries. The gap in innovation is, to no small extent, a result of moving pharmaceutical manufacturing offshore and basing competitive advantage on cheaper labor rather than developing and adopting advanced technologies. The lack of substantial drug manufacturing in the USA leads to diminished attention to its problems and needs. Symptomatically, a large multibillion-dollar public-private partnership network, Manufacturing USA, which spans from textile to artificial intelligence, does not include drug manufacturing, except its bio sector. At the same time, the public debate and governmental policies impose immense cost pressure on drug manufacturers. For example, the Generic Drug User Fee Act (GDUFA) and the FDA Drug Competition Action Plan (DCAP) are explicitly designed to address "market failure" by facilitating increased market competition. However, these efforts tend to push the industry to focus on cost-cutting measures such as moving production to low-cost locations while still using the traditional approach to manufacturing because of regulatory concerns.

Adopting advanced and innovative manufacturing tools would offset the costs of cheaper labor in developing countries, where cost savings due to low wages often translate into poor product quality. Instead of seeking low-cost labor, the industry's needs can be better served by a highly skilled and highly productive workforce capable of operating advanced manufacturing lines. The US FDA has placed its attention on continuous manufacturing because of its higher reliability and efficiency to manufacture drugs than the traditional laborintensive, multi-step batch process. On February 26, 2019, the FDA issued draft guidance entitled "Quality Considerations for Continuous Manufacturing" (6) to provide greater regulatory predictability and encouragement for the industry. This approach will offer significant additional savings by cutting long supply chains that are complex and difficult to manage. It will provide other advantages by being geographically closer to consumers and thus reducing shipping costs and carbon footprint. Most importantly, it will utilize the local labor force, instill confidence in the products made in America, and ultimately change the perception of the pharmaceutical industry in the eyes of the American public. To facilitate reshoring the supply chain utilizing new technologies, it is essential to engage academic science and engineering centers and create new ones that specifically focus on the design and development of materials and products and continuous manufacturing processes.

NIPTE Pharmaceutical Quality Assurance Index. It is well established that patients and the general public are often unable to assess and appreciate the quality of their medicines. Patients expect the quality of generic drugs to be the same as brand drugs. However, this expectation is often tarnished by regulatory violations, product recalls, and import alerts. The US FDA attempts to reinforce confidence in generics by blanket public statements that generic drugs are as safe and effective as brand name drugs. The effectiveness of such public health messages is questionable. For these and other reasons, the current environment forces the drug companies to compete primarily on cost rather than on both price and quality.

Drugs, particularly generic drugs, are made by various companies distributed across the globe in developed and emerging economies. The ability of the US FDA to maintain the same rigor of its inspections is limited. Thus, the assurance of quality is highly variable, and this variability is consequential $(7,8)$. The proposed Pharmaceutical Quality Assurance Index seeks to inform the consumer and contribute to improving the value of quality and its assurance. The Index is intended to provide a mechanism that would allow the consumers, actual buyers of drug products, such as insurers, governments, group purchasing organizations, and 


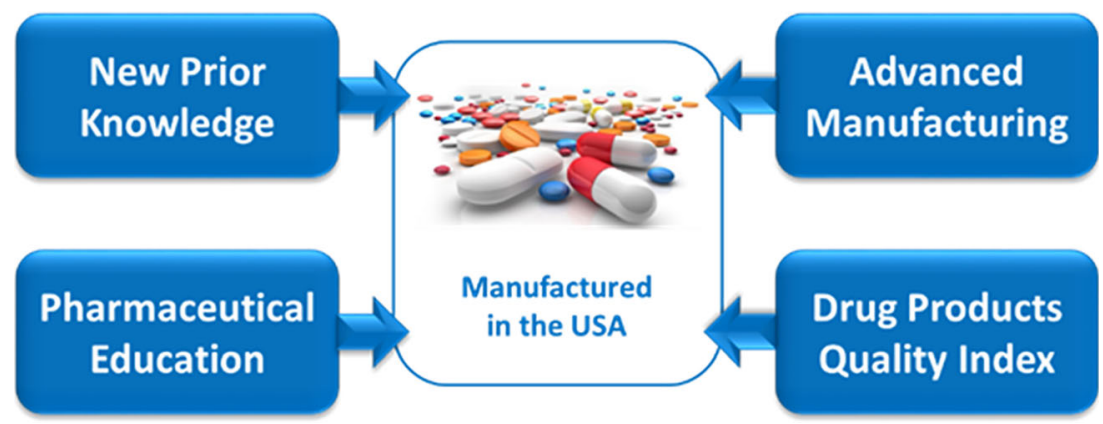

Fig. 1. Critical elements of a comprehensive strategy for reshoring pharmaceutical manufacturing

distributors, to make informed decisions based on the quality of drug products. Informed consumer and payor decisionmaking can also incentivize the industry to improve drug quality and minimize negative media coverage of their regulatory violations and external quality failures. That is, the Index can provide a greater incentive to operate fully in compliance with high-quality standards of medical products.

Pharmaceutical Education. Reviving domestic pharmaceutical manufacturing would require a highly trained and qualified workforce. In recent decades, the shift in demand due to globalization of the pharmaceutical supply chain, as well as insufficient research funding opportunities, caused significant reductions in relevant educational programs in US universities. That has to change, and colleges of pharmacy and chemical and pharmaceutical engineering have the opportunity to take the lead. This opportunity can present new growth of colleges of pharmacy that have lately experienced significant drops in applications for professional pharmacy practice programs. Furthermore, enrollment of international students in graduate programs is likely to decline due to the pandemic. To adequately meet the reshoring demand, focus on offering pharmaceutical science and engineering education opportunities for the US students, and current professionals are needed. A range of educational programs, a certificate to bachelor's, master's, and doctoral degrees, with emphasis on industrial and regulatory practice, is needed. The curricula for these educational offerings should be updated to ensure traditional pharmaceutical science disciplines integrate with contemporary pharmaceutical material science, product, and process design and engineering and biotechnology in the context of regulatory approval and inspection requirements. The NIPTE is already playing a significant role in establishing similar programs; for example, it has developed a Certification in Pharmaceutical Science and Technology, and it is currently available to industrial scientists and FDA review staff. Education, training, and experiences are foundational requirements under the Food, Drug, and Cosmetic Act (for example, 21 CFR 211.15) and critical to ensuring a science-based approach to the design, development, and manufacturing of quality drugs.

A federally supported public-private partnership is required to undertake this effort. As the only academic organization focusing on pharmaceutical science and manufacturing, the NIPTE is poised to play a significant role in implementing this approach. The US Government's role is critical in terms of providing leadership in the whole effort by introducing a wide range of incentives to the pharmaceutical industry to move manufacturing to the USA. The proposed approach is not against globalization. On the contrary, by creating and expanding a national robust and highly innovative manufacturing system that produces high-quality medical products, the USA will reclaim its leading status and provide an example that other nations will eventually follow.

\section{SUMMARY}

Reliable supply of quality pharmaceuticals is now clearly recognized as a national security need. Before the COVID-19 pandemic, the globalized supply chain for manufacturing of affordable medicines was under severe strain. In and beyond the COVID-19 pandemic, the globalized paradigm is at a precipice, in part because of the extreme vulnerabilities in the nation's dependence on foreign-sourced active pharmaceutical ingredients and drug products. To address these challenges, the NIPTE is engaged with its stakeholders to respond rapidly and contribute an additional source of critical drugs in short supply needed for treating COVID-19 patients. Furthermore, beyond the COVID-19 pandemic, the NIPTE is engaged in supporting the nation's need to reshore essential elements of the pharmaceutical supply chain. The ability of the NIPTE to be a "third leg of the stool" is in the maturity of its unique collaboration among the academic expertise in pharmaceutical science, technology, and engineering.

\section{REFERENCES}

1. US FDA Critical Path Initiative: Transforming the way FDAregulated products are developed, evaluated, and manufactured. Challenges and Opportunities Report - March 2004. https:// www.fda.gov/science-research/science-and-research-specialtopics/critical-path-initiative (Accessed May 11, 2020).

2. Hussain, A.S., Gurvich, V.J., and Morris, K., 2019. Pharmaceutical "new prior knowledge": twenty-first century assurance of therapeutic equivalence. AAPS Pharm Sci Tech, 20(3): 140 (2019). https://doi.org/10.1208/s12249-019-1347-6 (Accessed May 11, 2020).

3. S.3537 - Protecting Our Pharmaceutical Supply Chain from China Act of 2020. Introduced 03/19/2020. Moving American Pharmaceutical Production Out of China for the Health and Safety of Americans. https://www.congress.gov/bill/116th-congress/senate-bill/3537/text ().

4. H.R.6670 - Prescription for American Drug Independence Act of 2020. To provide for an exploration of strategies to increase domestic manufacturing and diversify the supply chain of critical 
drugs, and for other purposes. Introduced 05/01/2020. https:// www.govtrack.us/congress/bills/116/hr6670/text (Accessed May 11, 2020).

5. FDA reports more shortages of drugs used to put COVID-19 patients on ventilators. https://www.raps.org/news-and-articles/ news-articles/2020/4/fda-reports-more-shortages-of-drugs-usedto-put-co (Accessed May 11, 2020).

6. US FDA Draft Guidance for Industry. Quality Considerations for Continuous Manufacturing. February 2019, https:/www.fda.gov/ downloads/Drugs/GuidanceComplianceRegulatoryInformation/ Guidances/UCM632033.pdf. (Accessed May 11, 2020).
7. Gibson R, Singh JP. China Rx: exposing the risks of America's dependence on China for medicine. New York: Prometheus Books; 2018.

8. Eban K. Bottle of lies. New York: HarperCollins Publishers; 2019. $482 \mathrm{p}$.

Publisher's Note Springer Nature remains neutral with regard to jurisdictional claims in published maps and institutional affiliations. 